Massachusetts Institute of Technology in Cambridge and his team created a network map of interactions between 185 strains of Vibrionaceae bacteria. They found that antagonistic interactions were much less likely between strains that are as closely related as those within naturally occurring populations.

The authors suggest that the populations act as cohesive units that can defend themselves against other groups of bacteria. The coordination seems to have arisen through horizontal gene transfer, in which population members capable of producing antibiotics passed on antibiotic-resistance genes to their neighbours.

Science 337, 1228-1231 (2012)

$$
\text { MICROBIOLOGY }
$$

\section{Ecosystems compete}

Bacterial species seem to compete more than they cooperate.

Kevin Foster at the University of Oxford, UK, and Thomas Bell at Imperial College London tested the theory that different bacterial species can form cooperative 'superorganisms. The team measured the productivity - in terms of $\mathrm{CO}_{2}$ given off through respiration - of a range of multi-species microbial cultures. After both one week and one month, species in the mixtures were less productive than they would have been if grown separately, suggesting that social living comes at a cost. Curr. Biol. http://dx.doi. org/10.1016/j.cub.2012.08.005 (2012)

\section{A treatable form of autism}

A rare form of autism that is accompanied by epilepsy and intellectual disability could be treatable with dietary supplements.

Joseph Gleeson and Gaia
Novarino at the University of California, San Diego, and their team identified three affected families that carry mutated versions of a gene called $B C K D K$. The gene encodes an enzyme that slows the breakdown of branchedchain amino acids such as leucine and valine. Mice that lack both copies of the gene had low serum and brain levels of these amino acids, and showed neurological abnormalities and stunted growth. Enriching the animals' diets in branchedchain amino acids reversed these deficits.

Similar dietary enrichment normalized serum levels of branched-chain amino acids in people affected by the $B C K D K$ mutation.

Science http://dx.doi. org/10.1126/science.1224631 (2012)

\section{CONSERVATION BIOLOGY}

\section{Tigers and people can coexist}

As the world becomes more crowded, setting aside time, as well as space, for other species could help humans to live harmoniously alongside wildlife.

Jianguo Liu of Michigan State University in East Lansing and his team came up with the idea after analysing footage from motion-activated cameras they had set up in and around Nepal's Chitwan National Park. The team detected high levels of both human and tiger activity in the park, and found that the geographical activity patterns of the two species overlapped: any given camera was likely to collect images of both. Yet there was little conflict between humans and tigers in the park, probably because $80 \%$ of tiger detections occurred at night, when humans are generally at home. Outside the park, where humans are even thicker on the ground, $95 \%$ of tiger detections were at night.

Proc. Natl Acad. Sci. USA http://dx.doi.org/10.1073/ pnas.1210490109 (2012)

COMMUNITY CHOICE

The most viewed papers in science

\title{
Calm Sun promotes chilly winters
}

\section{Q HIGHLY READ \\ on www.agu.org 27 Aug-2 Sept}

Unusually cold central European winters - such as those of the past two years could be due to atmospheric circulation anomalies caused by weak solar activity.

Frank Sirocko of the Johannes Gutenberg University of Mainz, Germany, and his team compared historical records of freezing of the river Rhine with a time series of observed sunspot activity. The researchers found that 10 of the 14 major freezing events that have occurred since 1780 took place in or around years with minimal numbers of sunspots, when solar activity was weak.

The effects of weak solar activity may propagate to the lowest layer of Earth's atmosphere, leading to changes in pressure systems over the North Atlantic. These changes would favour the sustained flow of chilly Arctic air to central Europe during winter months, the team suggests. Geophys. Res. Lett. http://dx.doi.org/10.1029/2012GL052412 (2012)
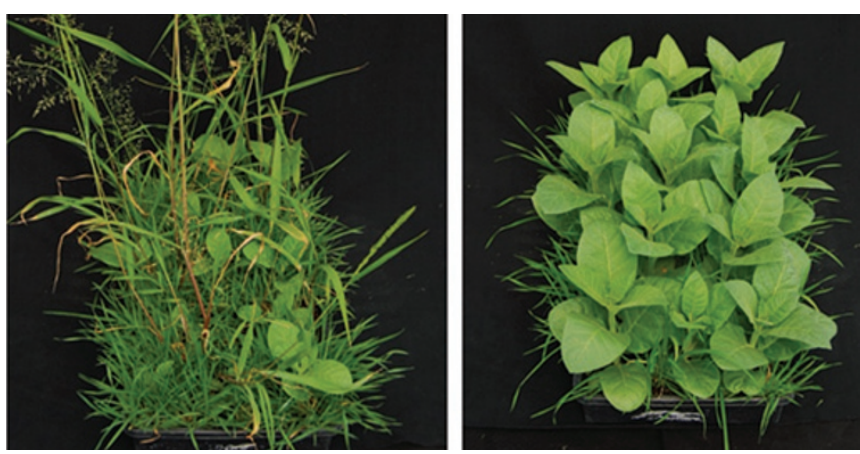

PLANT BIOTECHNOLOGY

\section{Engineered plants can use phosphite}

Many crops depend on phosphorus-based fertilizers and are threatened by herbicide-resistant weeds. Genetically modified plants that can digest an alternative phosphorus source that normally inhibits plant growth could solve both problems.

Damar López-Arredondo and Luis Herrera-Estrella at the National Polytechnic Institute's Centre for Research and Advanced Studies in Irapuato, Mexico, engineered the model plant Arabidopsis, and tobacco plants, to metabolize phosphite, in addition to the orthophosphate found in standard fertilizer. When phosphite was available, the transgenic plants needed $30-50 \%$ less phosphorus to generate the same amount of biomass as that produced in the presence of orthophosphate. The researchers also tested the transgenic plants against weeds. In the presence of orthophosphate, weeds dominated the transgenic plants, but with the addition of phosphite, transgenic tobacco plants easily outcompeted weeds (pictured).

Nature Biotechnol. http://dx.doi. org/10.1038/nbt.2346 (2012)

\section{$\rightarrow$ NATURE,COM}

For the latest research published by Naturevisit:

www.nature.com/latestresearch 